\title{
EDITORIAL
}

\section{Is the tide turning against breast screening?}

\author{
Karsten Juhl Jørgensen* \\ See related research by Nederend et al., http://breast-cancer-research.com/content/14/1/R10
}

\begin{abstract}
Herein I argue that mammographic screening has not delivered on its fundamental premise: to reduce the incidence of advanced breast cancer. Indeed, achieving this goal is required if screening is to reduce breast cancer mortality or mastectomy use. Rather, screening has caused substantial increases in the incidence of in situ and early invasive cancers. Moreover, evidence indicates that these screen-detected cancers are unlikely to be cases that were 'caught early', but instead represent women who would not have been diagnosed in the absence of screening and who, as a result, have received harmful, unnecessary treatment. If true, these observations raise the specter that screening creates breast cancer patients and that this practice carries little or no benefit.
\end{abstract}

\section{Introduction}

The rationale for breast screening with mammography is deceptively simple: catch the cancer early and reduce mortality from the disease and the need for mastectomies. But breast cancer is a complex disease, and complex problems rarely have simple solutions.

A key question is if screening can prevent metastasis, as this would reduce breast cancer fatalities. Another is if the screen-detected tumours that previously required a mastectomy are now small enough to allow breast conserving surgery. The fundamental premise for both objectives is that screening must reduce the incidence of advanced breast cancer. Whether such a reduction occurs in a long-running, organized, population-based breast screening programme is what Joost Nederend and colleagues explore in their study from The Netherlands [1].

\section{Current context}

Other researchers have questioned whether breast screening reduce the number of advanced cancers $[2,3]$.

*Correspondence: kj@cochrane.dk

The Nordic Cochrane Centre, Rigshospitalet, Dept 3343, Blegdamsvej 9, DK-2100 Copenhagen, Denmark
A claimed reduction in breast cancer mortality [4-6] as well as a reduction in the use of mastectomies $[7,8]$ have also been called into doubt in studies of populationbased breast screening. In addition, the detection of cancers that would otherwise not have developed into clinical, symptomatic disease (overdiagnosis) is now recognised as an important harm, also for invasive breast cancer $[9,10]$.

A recent systematic review of incidence trends in seven countries with at least seven years of screening [2] found that breast screening has not fulfilled its promise of fewer advanced breast cancers. It included The Netherlands, but not data from before organised screening was introduced in the late 1980s. Including data from 1980 to 2008 is a strength of the new study, as it allows reliable estimates of both pre- and post-screening incidence trends of advanced breast cancer. If the background incidence was increasing prior to screening, but stable during the screening period, screening may have prevented a further increase in advanced breast cancer. This seems not to have happened, either in The Netherlands or in other countries where data from the pre-screening period are available - for example, the United States and Norway [2]. A new study from Norway used the stepwise introduction of breast screening to compare the occurrence of stage 3 and 4 tumours in screened and nonscreened areas, with data available also from the prescreening era. The availability of a contemporary 'control group' circumvents the usual problems related to using stage distribution over time due to changing definitions and diagnostic methods. In Norway, there was a reduction in the occurrence of stage 3 and 4 tumours in screened areas in recent years compared to the prescreening years, but an identical reduction was seen in the non-screened areas [11]. The authors also found evidence of substantial overdiagnosis of invasive breast cancers in Norway and ended their paper by raising the question of whether mammography screening programmes should exist.

Some studies have concluded that a reduction in advanced breast cancer has occurred, also in The Netherlands [12], but this is not correct [13]. The authors concluded that screening had reduced the incidence of cancers with metastases but they split these cancers into 
two groups: those above and those below $20 \mathrm{~mm}$ in diameter. When the data from the two groups were added, there was no reduction in incidence of cancers with metastases [13]. In fact, the combined incidence was identical for the first and last year reported (1989 and 1997) [13]. Another frequent fallacy is to compare the percentages of advanced breast cancers before and after screening. This neglects that screening finds many small, overdiagnosed cancers and will provide misleading results [13].

\section{Does breast screening 'catch it early'?}

The stable incidence of advanced breast cancer is in stark contrast to the massive increases in the incidence of in situ and early breast cancer. When screening is introduced, the incidence of early stage breast cancer doubles, and it increases several-fold for in situ cases [8]. This has been seen everywhere screening has been introduced [9]. The increases do not disappear or diminish, even with follow-up over decades [9], and they coincide with screening even though its introduction is separated by many years between countries [9].

According to previous screening theory, these massive increases should prevent late stage disease, but despite more than 20 years of breast screening, this has not happened, which is not surprising if we consider the biology of breast cancer [3].

Breast screening brings forward the time of diagnosis only slightly compared to the fact that, on average, the woman has harboured the tumour for more than 20 years before it is detected $[3,13]$. When detected at screening, about one-third of the cancers have already metastasized $[3,13]$. In the randomised trials, tumours in the control group were $21 \mathrm{~mm}$ on average, and in the screened group they were $16 \mathrm{~mm}$. Screening programmes today detect breast cancers that are a little over $10 \mathrm{~mm}$ on average, rather than $20 \mathrm{~mm}$ for clinically detected disease [14]. This represents a reduction of 1 to 2 volume doublings of the 32 necessary doublings to reach $20 \mathrm{~mm}$ [15], which is equivalent to a few months' growth for aggressive, fastgrowing cancers [14] that can therefore easily 'slip through the screen'.

The true difference in size between screen-detected and clinically detected breast cancers in a screened population must be less than $10 \mathrm{~mm}$, however. Overdiagnosis of small breast cancers artificially inflates the difference, and length bias means that screening preferentially detects small, slow-growing cancers, simply because there is more time to detect them. Similarly, the clinically detected cancers include the fast-growing interval cancers and attendees are those that already see their doctor when they notice something is wrong (selection bias, or the healthy screenee effect).

\section{What caused the large decline in breast cancer mortality?}

Despite high screening participation since the mid-1980s, breast cancer mortality in Sweden was reduced by only $16 \%$ from 1989 to 2006 in women aged 50 to 69 years, much less than in Denmark (26\%) and Norway (23\%), which had only limited screening - for example, $20 \%$ of women aged 50 to 69 years were offered screening in Denmark [16]. It is a general trait that the average reduction in breast cancer mortality in Europe has been almost twice as large in younger, non-screened age groups as in those screened, and equally large in countries with and without screening [16]. The laurels for this remarkable achievement should go to improved treatment of the sick, not screening of the healthy.

\section{Summing up breast screening}

Screening has not delivered on its promises. The risk of being diagnosed with advanced breast cancer today is the same as before screening, which is why screening has not reduced breast cancer mortality [5,6] or mastectomy use [7]. However, the risk of being diagnosed with breast cancer has increased by $50 \%$ in the screened age group due to overdiagnosis [9], with severe consequences for those who experience it. Screening for breast cancer has turned out to be very complex and hard to justify.

Competing interests

The author declares that they have no competing interests.

Published: 13 July 2012

References

1. Nederend J, Duijm LEM, Voogd AC, Groenewoud JH, Jansen FH, Louwman MWJ: Trends in incidence and detection of advanced breast cancer at biennial screening mammography in The Netherlands: a population based study. Breast Cancer Res 2012, 14:R10.

2. Autier P, Boniol M, Middleton R, Doré JF, Héry C, Zheng T, Gavin A: Advanced breast cancer incidence following population based mammographic screening. Ann Oncol 2011, 22:1726-1735.

3. Gøtzsche PC, Jørgensen KJ, Zahl PH, Mæhlen J: Why mammography screening hasn't lived up to expectations from the randomised trials. Cancer Causes Contr 2012, 23:15-21.

4. Autier P, Boniol M, Gavin A, Vatten L: Breast cancer mortality in neighbouring European countries with different levels of screening but similar access to treatment: trend analysis of WHO mortality database. BMJ 2011, 343:d4411.

5. Jørgensen KJ, Zahl PH, Gøtzsche PC: Breast cancer mortality in organised mammography screening in Denmark. A comparative study. BMJ 2010, 340:c1241

6. Kalager M, Zelen M, Langmark F, Adami HO: Effect of screening mammography on breast-cancer mortality in Norway. N Engl J Med 2010, 363:1203-1210.

7. Surhke P, Mæhlen J, Schlichting E, Jørgensen KJ, Gøtzsche PC, Zahl PH: Mammography screening and surgical breast cancer treatment in Norway: comparative analysis of cancer registry data. BMJ 2011, 343:d4692.

8. Jørgensen KJ, Keen J, Gøtzsche PC: Is mammographic screening justifiable considering its substantial overdiagnosis rate and minor effect on mortality? Radiology 2011, 260:621-627.

9. Jørgensen KJ, Gøtzsche PC: Overdiagnosis in publicly organised mammography screening programmes: systematic review of incidence trends. BMJ 2009, 339:b2587.

10. Morrell S, Barratt A, Irwing L, Howard K, Biesheuvel C, Armstrong B: Estimates 
of overdiagnosis of invasive breast cancer associated with screening mammography. Cancer Causes Control 2010, 21:275-282.

11. Kalager M, Adami HO, Bretthauer M, Tamimi RM: Overdiagnosis of invasive breast cancer due to mammography screening: results from the Norgwegian screening program. Ann Int Med 2012, 156:491-499.

12. Fracheboud J, Otto SJ, van Dijck JA, Broeders MJ, Verbeek AL, de Koning HJ; National Evaluation Team for Breast cancer screening (NETB): Decreased rates of advanced breast cancer due to mammography screening in the Netherlands. Br J Cancer 2004, 91:861-867.

13. Gøtzsche PC: Mammography Screening: Truth, Lies and Controversy. London: Radcliffe Publishing Ltd; 2012

14. Bailey SL, Sigal BM, Plevritis SK: A simulation model investigating the impact of tumor volume doubling time and mammographic tumor detectability on screening outcomes in women aged 40-49 years. J Natl Cancer Inst 2010, 102:1263-1271
15. Mittra I, Baum M, Thornton H, Houghton J: Is clinical breast examination an acceptable alternative to mammographic screening? BMJ 2000, 321:1071-1073.

16. Autier P, Boniol M, La Vecchia C, Vatten L, Gavin A, Héry C, Heanue M: Disparities in breast cancer mortality trends between 30 European countries: retrospective trend analysis of WHO mortality database. BMJ 2010, 341:C3620.

\section{doi:10.1186/bcr3212}

Cite this article as: Jørgensen $\mathrm{KJ}$ : Is the tide turning against breast screening? Breast Cancer Research 2012, 14:107. 